\title{
COOPERATION-COMPETITION MODEL OF TRANSPORTATION CONSTRUCTION PROJECT FROM THE VIEWPOINT OF BUDGET ALLOCATION
}

\author{
Maw-Cherng Lin \\ Department of Rapid Transit Systems, Taipei City Government, Taipei City, Taiwan, R.O.C \\ Edward Ming-Yang Wu \\ Department of Civil and Ecological Engineering, I-Shou University, Kaohsiung County, Taiwan, R.O.C., \\ edmywu@isu.edu.tw \\ Junn-Yuan Teng \\ Department of Industrial Engineering and Management Information, Huafan University, Taipei County, Taiwan, R.O.C \\ Wen-Chih Huang \\ Department of Industrial Engineering and Management Information, Huafan University, Taipei County, Taiwan, R.O.C
}

Follow this and additional works at: https://jmstt.ntou.edu.tw/journal

Part of the Civil and Environmental Engineering Commons

\author{
Recommended Citation \\ Lin, Maw-Cherng; Wu, Edward Ming-Yang; Teng, Junn-Yuan; and Huang, Wen-Chih (2010) "COOPERATION- \\ COMPETITION MODEL OF TRANSPORTATION CONSTRUCTION PROJECT FROM THE VIEWPOINT OF BUDGET \\ ALLOCATION," Journal of Marine Science and Technology. Vol. 18: Iss. 6, Article 17. \\ DOI: 10.51400/2709-6998.1951 \\ Available at: https://jmstt.ntou.edu.tw/journal/vol18/iss6/17 \\ This Research Article is brought to you for free and open access by Journal of Marine Science and Technology. It has been \\ accepted for inclusion in Journal of Marine Science and Technology by an authorized editor of Journal of Marine Science and \\ Technology.
}




\section{COOPERATION-COMPETITION MODEL OF TRANSPORTATION CONSTRUCTION PROJECT FROM THE VIEWPOINT OF BUDGET ALLOCATION}

\section{Acknowledgements}

The authors are grateful for the helpful comments made by the editor of this journal and the anonymous reviewers. We also like to thank colleagues in the department for their valuable feedback 


\title{
COOPERATION-COMPETITION MODEL OF TRANSPORTATION CONSTRUCTION PROJECT FROM THE VIEWPOINT OF BUDGET ALLOCATION
}

\author{
Maw-Cherng Lin*, Edward Ming-Yang Wu**, Junn-Yuan Teng***, \\ and Wen-Chih Huang****
}

Key words: transportation construction project, budget allocation, cooperation-competition model, group decision-making.

\begin{abstract}
The resource-allocation principle, which combines policy and budget, is the basic criterion for public-policy planning of a government in the present era. It can make the policy target, construction project, and budget work together closely. The transportation construction project has a certain degree of relativity under a target; so when selecting projects, a division of levels should be carried out according to the priority of project desirability [19]. Furthermore, the relativity of potential cooperation-competition between projects must be identified to avoid any waste of limited resources. This is the focus point that will be discussed in this paper. Lastly, this research classified the cooperation-competition relation of a construction project into independent project, complementary project, overlapping project, and common complementary overlapping project. This research made a subjective judgment based on relevant domain experts' professional accomplishments, and then identified the experts' consensus.
\end{abstract}

\section{INTRODUCTION}

Investment planning problems in the public sector are characterized by being multi-stage, multi-objective, multidecision-maker, and uncertain. As for resource-allocation

Paper submitted 03/27/09; revised 07/07/10; accepted 07/14/10. Author for correspondence: Edward Ming-Yang Wu (e-mail: edmywu@isu.edu.tw).

*Department of Rapid Transit Systems, Taipei City Government, Taipei City, Taiwan, R.O.C.

**Department of Civil and Ecological Engineering, I-Shou University, Kaohsiung County, Taiwan, R.O.C.

***Department of Industrial Engineering and Management Information, Huafan University, Taipei County, Taiwan, R.O.C.

****Department of Transportation Technology and Management, Kainan University, Taoyuan County, Taiwan, R.O.C. problems of transportation construction, not all transportation systems have fixed proportions, and the priority should be given to transportation systems that have high system efficiency and a high degree of policy target accomplishment. Regarding public construction projects, besides being classified as special budget projects, general investment programs can be classified into several annual executive plans. The available stock size can be inferred definitely in the first year, while in the second year, the effect of uncertain factors starts to increase. As economic growth may decline, remain the same, or increase, different states can occur in resource supply, so the selected advantageous projects would also be different. The transportation construction project has a certain degree of relativity under a target; so when selecting projects, a division of levels should be carried out according to the priority of project desirability [19]. In addition, the relativity of potential cooperation-competition between projects must be identified to avoid the waste of limited investment resources. This is the point that will be discussed in this paper.

\section{LITERATURE REVIEW}

In public-sector investment planning, many countries and regions, including Taiwan, still take CBA (cost-benefit analysis) as the main evaluation tool to seek the optimum of a single objective, such as "maximum social net benefit" or "minimum social cost." However, the primary problem of CBA is whether the method of converting to a monetary value is appropriate; in other words, the CBA assumes all the data used in analyses can be defined and scaled accurately; CBA does not allow dynamic uncertainties, such as the inflation rate, unstable fuel prices, and changes in wages. Secondly, CBA does not evaluate the range of financial risk or possible net benefit [15]. In addition, the means of selecting the appropriate rate of discount to infer the net present value has been disputed by economists $[1,6,9,12]$. In this complicated social structure, the future is full of many uncertainties and risks, and it is very difficult to measure unquantifiable or invisible targets. Voogd 
[21] took the Netherlands as an example. At the end of the 1970s, the evaluations of the Dutch government of many policies had shifted from CBA to a multi-criteria evaluation method; the policy evaluations included a Waste Disposal Program, a Leisure and Recreation Plan, a Regional Construction Project, a Trafficking Project, and a Water Resource Management Plan. Even the annual road investment plan was selected through the multi-criteria evaluation method.

Formerly, in the multi-objective public-investment program selection, the analysis of the applied mathematics optimum could be classified into Multi-Attribute Utility Theory (MAUT) and Multi-Objective Mathematical Programming (MOMP). The MAUT method constructs the single-attribute utility function through the probability measuring method by evaluating the attribute and then constructs the multi-attribute utility function through the utility-decomposition method, such as the additive and multiplicative multi-attribute utility function [10], for example, Morisugi et al. [14], and Pearman et al. [16] for road-investment programs. The MOMP method constructs the objective function (linear or nonlinear) to be achieved according to the selected decision variables (which may be a real number, an integer, a mixed integer, or the integers $0-1$ ), and then obtains the required solution (non-inferior solution, preference solution, approximate solution, or optimal solution) through the mathematical solution method (e.g., vector-maximization method, interaction or conversation method, heuristic solution, linear programming method and non-linear programming [4, 8, 22]. For example, Leinbach and Cromley [13] applied the weighting preemptive goal programming to the selection of road-investment plans for 75 regions in Indonesia. Khorramshaphsol and Steiner [11] proposed the Delphi goal programming, and carried out the selection of suburban roadinvestment plans. Tzeng et al. [20] and Teng et al., [18] used a multiobjective programming approach for transportation investment alternatives selection. Whether applying MAUT or MOMP to public-sector investment planning, previous research has focused on single-stage investment programs and has not considered the problem of limited resources in the applications of MAUT and partial MOMP.

In past research that applies MCDM (multi-criteria decision making) to public-sector investment decision problems, although the relativity of public investment programs was discussed, the cooperation-competition relativity and the effect on goal achievement were not analyzed in detail. In their review, Baker and Freeland [2] listed many constraints to the investment project selection model. Gear [7] classified the relativity of investment projects into the impact of factors inside the organization and the impact of the environment outside the organization; the former refers to the impact on resource demand or objective benefit, and the latter refers to the impact on the change in social economy (e.g., GNP, inflation rate, and per capita income). Fayette [5] proposed the conception of non-independent investment project selection in a multi-criteria feature while Carlsson [3] classified the rela- tivity of objective achievement into conflict objectives, mutually supportive goals, and unilaterally supportive goals when discussing the selection of relevant investment projects. Carlsson used the fuzzy-set theory for analyses to find the most satisfactory project.

In public-sector investment-decision problems, there is usually a certain relativity among public investment programs. For example, in transportation investment, there is a certain overlapping of the degree of substitutability between highspeed railways and expressways; and there is a certain complementarity between expressways and ports. Therefore, this research aimed to identify the cooperation-competition relation between construction projects when proceeding with transportation construction investment decision problems with the premise of the multi-objective characteristic, so as to work with the priority of projects' desirability for a division of levels [19], and avoid any waste of limited investment resources.

\section{MODEL AND HYPOTHESES}

\section{Cooperation-Competition Classification of Transportation Construction Project}

Based on the literature review and interviews with experts, this research classified the cooperation-competition relation of construction projects into four kinds of construction project (independent project, complementary project, overlapping project, and common complementary overlapping project). The research then made a subjective judgment based on relevant domain experts' professional accomplishments, and subsequently identified the experts' consensus.

\section{1) Independent Construction Project}

In an independent construction project, the achieved performance of the project at $q$ objectives is free from the effect of other projects. Meanwhile, it does not affect other projects. If the aggregation formed by all independent construction projects is indicated by $\Gamma^{I}$, and if construction project $t_{i} \in \Gamma^{I}(i=1$, $2, \ldots, n)$, then it means $t_{i}$ would not affect other construction projects $t_{i^{\prime}}\left(i^{\prime}=1,2, \ldots, n\right)$, and construction project $t_{i^{\prime}}$ would not affect $t_{i}$. The effect of investment benefit is shown in Fig. 1(a).

\section{2) Complementary Construction Project}

In a complementary construction project, the achieved performance of the construction project in relation to an objective is affected by at least one project, or it affects at least one construction project; when two interactional construction projects have investment at the same time, the achieved performance of the objective can be increased. If the aggregation formed by all complementary construction projects is indicated by $\Gamma^{C}$, and if construction project $t_{i}, t_{i^{\prime}} \in \Gamma^{C}$, then $t_{i} C t_{i^{\prime}}$ means construction project $t_{i}$ has a complementary effect on construction project $t_{i}$, and $t_{i} \mathrm{C}_{i}$ means construction project $t_{i^{\prime}}$ has a complementary effect on construction project $t_{i}$. The investment benefit effect of a complementary construction 

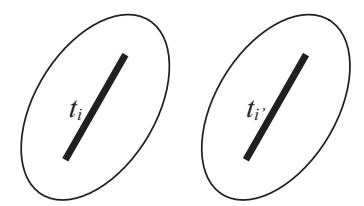

(a) Independent projects

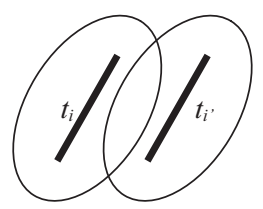

(c) Overlapping projects

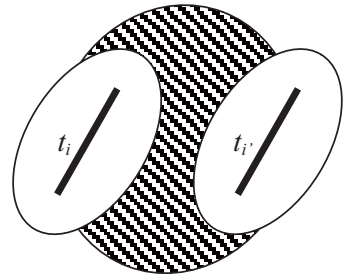

(b) Complementary projects

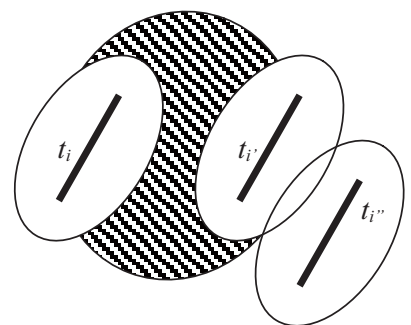

(d) Common complementary overlapping projects
Fig. 1. Effects of different cooperation-competition transportation construction projects on investment returns.

project is shown in Fig. 1(b); the slash represents the increased performance of $t_{i} C t_{i^{\prime}}$ and $t_{i} C t_{i}$.

\section{3) Overlapping Construction Project}

In an overlapping construction project, the achieved performance of the project at a certain objective and part or all of it can be achieved by other projects. Because the overlapping construction project does not increase the achievement value of objective performance, it can only replace part or all of the achievement values of another project with part or all of a project. If the aggregation formed by all overlapping construction projects is indicated by $\Gamma^{O}$, and if construction project $t_{i}, t_{i^{\prime}} \in \Gamma^{O}$, then $t_{i} O t_{i^{\prime}}$ means construction project $t_{i}$ has a substitutional effect on construction project $t_{i}$, and $t_{i} O t_{i}$ means that construction project $t_{i}$ has a substitutional effect on construction project $t_{i}$. The investment benefit effect of the overlapping construction project is shown in Fig. 1 (c). The intersection represents the performance of the mutually replaceable part of $t_{i} O t_{i^{\prime}}$ or $t_{i} O t_{i}$.

\section{4) Common Complementary Overlapping Project}

In a common complementary overlapping project, the project is complementary to and substitutable for other construction projects with the same or different goals. If the aggregation formed by all common complementary overlapping projects is indicated by $\Gamma^{C O}$, and if construction project $t_{i} \in$ $\Gamma^{C O}, t_{i^{\prime}} \in \Gamma^{C}$, and $t_{i^{\prime \prime}} \in \Gamma^{O}$, then $t_{i} C t_{i^{\prime}}$ and $t_{i^{\prime}} O t_{i^{\prime \prime}}$ mean that construction project $t_{i}$ has a complementary effect on construction project $t_{i^{\prime}}$ and construction project $t_{i^{\prime}}$ has a substitutional effect on construction project $t_{i^{\prime \prime}}$; or $t_{i} C t_{i}$ and $t_{i^{\prime \prime}} C t_{i^{\prime}}$ mean that construction project $t_{i^{\prime}}$ has a complementary effect on construction project $t_{i}$ and construction project $t_{i^{\prime \prime}}$ has a substitutional effect on construction project $t_{i}$. So $\Gamma^{C O}$ is the intersection of $\Gamma^{C}$ and $\Gamma^{O}$, that is,

$$
\Gamma^{C O}=\Gamma^{C} \cap \Gamma^{O}
$$

The investment benefit effect of this common complementary overlapping project is shown in Fig. 1(d). The calculation of executive performance includes the increase in complementary aspects and the decrease in substituted aspects (overlapping part). Therefore, among the four kinds of construction projects, as long as the complementary project $\Gamma^{C}$ and overlapping project $\Gamma^{O}$ are determined, the independent project $\Gamma^{I}$ and common complementary overlapping construction project $\Gamma^{C O}$ can be determined according to the feature of the aggregation, that is,

$$
\Gamma^{I}=\frac{\Gamma^{T}}{\left(\Gamma^{C} \cup \Gamma^{O} \cup \Gamma^{C O}\right)}
$$

in which $\Gamma^{C O}=\Gamma^{C} \cap \Gamma^{O}, \Gamma^{T}=\left\{t_{1}, t_{2}, \ldots, t_{n}\right\}$ is the aggregation formed by $n$ construction projects.

\section{Theoretical Hypothesis}

Let us assume that $d c_{i i i^{\prime}}^{j k}$ and $d o_{i i^{\prime}}^{j k}$ denote the judgment value for expert $E_{j}(j=1,2, \ldots, m)$ to judge whether construction projects $t_{i}$ and $t_{i^{\prime}}\left(i, i^{\prime}=1,2, \ldots, n ; i \neq i^{\prime}\right)$ are complementary projects and overlapping projects, respectively, under the goal $G_{k}(k=1,2, \ldots, q)$. If the value of $d c_{i i^{\prime}}^{j k}$ or $d o_{i i^{\prime}}^{j k}$ is 1 , then construction projects $t_{i}$ and $t_{i}$ are complementary projects or overlapping projects; if the value of $d c_{i i^{\prime}}^{j k}$ or $d o_{i i^{\prime}}^{j k}$ is 0 , then construction projects $t_{i}$ and $t_{i}$ are neither complementary projects nor overlapping projects. That is,

$$
\begin{aligned}
d c_{i i^{\prime}}^{j k} & =\left\{\begin{array}{l}
1, \text { if } t_{i} C t_{i^{\prime}} \text { or } t_{i^{\prime}} C t_{i} \\
0, \text { others }
\end{array}\right. \\
d o_{i i^{\prime}}^{j k} & =\left\{\begin{array}{l}
1, \text { if } t_{i} O t_{i^{\prime}} \text { or } t_{i^{\prime}} O t_{i} \\
0, \text { others }
\end{array}\right.
\end{aligned}
$$

According to judgment with pairwise comparison ${ }^{1}, m$ binary complementary judgment matrices $D C^{j k}$ and binary overlapping judgment matrices $D O^{j k}$ can be obtained under each goal, that is,

$$
D C^{j k}=\left\{d c_{i i^{\prime}}^{j k} \mid i, i^{\prime} \in \Gamma^{T} ; i \neq i^{\prime}\right\}, \forall j, k
$$

${ }^{I}$ It is very difficult to judge all the projects when there are many projects, and the error in judgment can increase greatly. Experts, therefore make a comparison of a certain attribute of things at the same time and keep their judgments in a relatively coincident foundation. The pairwise comparison is therefore likely to cause minimum error [17]. 


$$
D O^{j k}=\left\{d o_{i i^{\prime}}^{j k} \mid i, i^{\prime} \in \Gamma^{T} ; i \neq i^{\prime}\right\}, \forall j, k
$$

If $D C^{T i}$ and $D O^{T i}$ are the synthetic judgment matrix for $m$ experts to judge whether $n$ construction projects are complementary projects and overlapping projects to each other under the goal $G_{k}$, then

$$
\begin{aligned}
& D C^{T i}=\left\{d c_{i i^{\prime}}^{T k} \mid d c_{i i^{\prime}}^{T k}=\sum_{j=1}^{m} d c_{i i^{\prime}}^{j k} ; i, i^{\prime} \in \Gamma^{T} ; i \neq i^{\prime}\right\}, \forall k \\
& D O^{T i}=\left\{d o_{i i^{\prime}}^{T k} \mid d o_{i i^{\prime}}^{T k}=\sum_{j=1}^{m} d o_{i i^{\prime}}^{j k} ; i, i^{\prime} \in \Gamma^{T} ; i \neq i^{\prime}\right\}, \forall k
\end{aligned}
$$

Experts from different fields hold different views on how to determine whether two construction projects are complementary or overlapping. Therefore, this research adopted the method commonly recognized by many experts. In other words, $d c_{i i^{\prime}}^{T k}$ and $d o_{i i^{\prime}}^{T k}$ must be above a certain value, $\theta$ (the number of majority of experts), thus

$$
\begin{aligned}
& d c_{i i^{\prime}}^{T k} \geq \theta, 1 \leq \theta \leq m \\
& d o_{i i^{\prime}}^{T k} \geq \theta, 1 \leq \theta \leq m
\end{aligned}
$$

in which value $\theta$ can be determined by $m$ experts jointly through discussion, this research being confirmed according to majority rule ${ }^{2}$; if the majority adopts it, then value $\theta$ can be determined through the following equation:

$$
\theta=\left\{\begin{array}{l}
(m / 2)+1, m \text { is an even number } \\
{[(m-1) / 2]+1, m \text { is an odd number }}
\end{array}\right.
$$

After the option of majority rule, the complementary common judgment matrix $D C_{c o n}^{k}$ and overlapping common judgment matrix $D O_{c o n}^{k}$ based on the common understanding of $\mathrm{R}$ experts under the goal $G_{k}(k=1,2, \ldots, q)$ can be obtained as follows:

$$
\begin{aligned}
& D C_{c o n}^{k}=\left\{d c_{i i^{\prime}}^{c k} \mid d c_{i i^{\prime}}^{c k}=1,0 ; i, i^{\prime} \in \Gamma^{T} ; i \neq i^{\prime}\right\}, \forall k \\
& D O_{c o n}^{k}=\left\{d o_{i i^{\prime}}^{c k} \mid d o_{i i^{\prime}}^{c k}=1,0 ; i, i^{\prime} \in \Gamma^{T} ; i \neq i^{\prime}\right\}, \forall k
\end{aligned}
$$

In which

$$
d c_{i i^{\prime}}^{c k}=\left\{\begin{array}{l}
1, d c_{i i^{\prime}}^{T k} \geq \theta \\
0, d c_{i i^{\prime}}^{T k}<\theta
\end{array}\right.
$$

$$
d o_{i i^{\prime}}^{c k}=\left\{\begin{array}{l}
1, d o_{i i^{\prime}}^{T k} \geq \theta \\
0, d o_{i i^{\prime}}^{T k}<\theta
\end{array}\right.
$$

Therefore, as long as the value of the $D C_{c o n}^{k}$ and $D O_{c o n}^{k}$ matrix element $d c_{i i^{\prime}}^{c k}$ and $d o_{i i^{\prime}}^{c k}$ is 1 , then construction projects $t_{i}$ and $t_{i^{\prime}}$ are complementary projects or overlapping projects on the performance achievement of goal $G_{k}$ based on the common judgment of $m$ experts; if the value of elements $d c_{i i^{\prime}}^{c k}$ and $d o_{i i^{\prime}}^{c k}$ is 0 , then construction projects $t_{i}$ and $t_{i^{\prime}}$ are not complementary projects or overlapping construction projects on the performance achievement of goal $G_{k}$ according to the common judgment of $m$ experts.

\section{Determination of Correlativity of Complementary Projects or Overlapping Projects}

The cooperation-competition relation between construction projects can be judged by experts aiming at the correlativity between complementary projects and overlapping projects after the said separation, and then find out the correlativity identified by most experts based on the common understanding of most experts.

According to the obtained complementary construction project $\Gamma^{C}$ and overlapping construction project $\Gamma^{O}$ aggregation, experts can judge the degree of complementarity and degree of overlap between the construction projects in aggregations $\Gamma^{C}$ and $\Gamma^{O}$. The method adopted in this part is the same as that for distinguishing the cooperation-competition relation between construction projects, and it still uses the comparison method of pairwise projects for judgment.

Let us assume that $\alpha_{i i^{\prime}}^{j k}$ and $\beta_{i i^{\prime}}^{j k}$ represent expert $E_{j}(j=1$, $2, \ldots, m)$ judging the potential degree of complementarity and degree of substitutability of construction projects $t_{i}$ and $t_{i^{\prime}}\left(i, i^{\prime}=\right.$ $\left.1,2, \ldots, n ; i \neq i^{\prime}\right)$ in aggregations $\Gamma^{C}$ and $\Gamma^{O}$ under the goal $G_{k}(k=$ $1,2, \ldots, q)$. Thus, $m$ degree of complementarity judging matrices $C^{j k}$ and degree of overlap judging matrices $O^{j k 3}$ can be obtained as follows:

$$
\begin{aligned}
& C^{j k}=\left\{\alpha_{i i^{\prime}}^{j k} \mid 0 \leq \alpha_{i i^{\prime}}^{j k} \leq 1 ; i, i^{\prime} \in \Gamma^{C}\right\}, \forall j, k \\
& O^{j k}=\left\{\beta_{i i^{\prime}}^{j k} \mid 0 \leq \beta_{i i^{\prime}}^{j k} \leq 1 ; i, i^{\prime} \in \Gamma^{O}\right\}, \forall j, k
\end{aligned}
$$

If $\alpha_{i i^{\prime}}^{j k}$ and $\beta_{i i^{\prime}}^{j k}$ value is 0 , then expert $j$ thinks that construction project $t_{i}$ and construction project $t_{i^{\prime}}$ have no degree of complementarity or degree of overlap on the achievement of goal $G_{k}$. If $\alpha_{i i^{\prime}}^{j k}$ and $\beta_{i i^{\prime}}^{j k}$ value is close to 1 , it means a higher degree of complementarity or degree of overlap; in contrast, if it is close to 0 , it means a lower degree of complementarity or degree of overlap.

\footnotetext{
${ }^{2}$ The majority rule can also adopt over two-thirds principle or over three-quarters principle, according to the degree of consensus to be achieved. ${ }^{3} C^{j k}$ and $O^{j k}$ matrices are asymmetric matrix, that is, the $\alpha_{i i}^{j k}$ value may not be the same as the $\alpha_{i{ }^{\prime} i}^{j k}$ value, or $\beta_{i i}^{j k}$ maynot be the same as the $\beta_{i \prime}^{j k}$ value; it is mainly because $t_{i} C_{i^{\prime}}$ and $t_{i^{\prime}} C t_{i}$ degrees, or $t_{i} O t_{i^{\prime}}$ and $t_{i^{\prime}}$ Ot $t_{i}$ degrees may not be the same.
} 
In the complementary construction project $\Gamma^{C}$, the degree of complementarity is likely to have $m$ opinions due to $m$ experts participating in the evaluation. If the $m$ judgment values are arranged from maximum to minimum, then $m$ experts' opinions on the synthetic judgment matrix $C^{T k}$ of the degree of complementarity can be obtained as follows:

$$
C^{T k}=\left\{\hat{\alpha}_{i i^{\prime}}^{j k} \mid i, i^{\prime} \in \Gamma^{C} ; j=1,2, \ldots, m\right\}, \forall k
$$

where

$$
\begin{aligned}
& \hat{\alpha}_{i i^{\prime}}^{j k}=\left\{\hat{\alpha}_{i i^{\prime}}^{1 k} \geq \hat{\alpha}_{i i^{\prime}}^{2 k} \geq \ldots \geq \hat{\alpha}_{i i^{\prime}}^{m k}\right\} \\
& \left.\hat{\alpha}_{i i^{\prime}}^{1 k}=\max _{j=1,2, \ldots, m} \operatorname{imum}_{i i^{\prime}}\right\} \\
& \hat{\alpha}_{i i^{\prime}}^{m k}=\min _{j=1,2, \ldots, m}^{j k}\left\{\alpha_{i i^{\prime}}^{j k}\right\}
\end{aligned}
$$

Similarly, the synthetic judgment matrix $O^{T k}$ of degree of substitutability in the overlapping construction project $\Gamma^{O}$ is as follows:

$$
O^{T k}=\left\{\hat{\beta}_{i i^{\prime}}^{j k} \mid i, i^{\prime} \in \Gamma^{O} ; j=1,2, \ldots, m\right\}, \forall k
$$

where

$$
\begin{aligned}
& \hat{\beta}_{i i^{\prime}}^{j k}=\left\{\hat{\beta}_{i i^{\prime}}^{1 k} \geq \hat{\beta}_{i i^{\prime}}^{2 k} \geq \ldots \geq \hat{\beta}_{i i^{\prime}}^{m k}\right\} \\
& \hat{\beta}_{i i^{\prime}}^{1 k}=\max _{j=1,2, \ldots, m} \operatorname{imum}_{i i^{\prime}}\left\{\beta_{i i^{j k}}^{j k}\right. \\
& \left.\hat{\beta}_{i i^{\prime}}^{m k}=\min _{j=1,2, \ldots, m} \operatorname{imum}_{i i^{\prime}}\right\}
\end{aligned}
$$

Since $m$ experts have $m$ different judgment values on the degree of complementarity of a complementary construction project and the degree of substitutability of an overlapping construction project, how to determine the final degree of complementarity and degree of overlap is an important issue. This research adopted the majority rule to determine the common opinion of most experts.

On the performance achievement of goal $G_{k}$, the degree of complementarity $C C_{i i^{\prime}}^{k}\left(i, i^{\prime} \in \Gamma^{C}\right)$ and degree of overlap $O C_{i i^{\prime}}^{k}\left(i, i^{\prime} \in \Gamma^{O}\right)$ of construction projects $t_{i}$ and $t_{i^{\prime}}$ can be determined through following equation:

$$
\begin{aligned}
& C C_{i i^{\prime}}^{k}=\hat{\alpha}_{i i^{\prime}}^{\theta k}, 1 \leq \theta \leq m ; i, i^{\prime} \in \Gamma^{C} ; \forall k \\
& O C_{i i^{\prime}}^{k}=\hat{\beta}_{i i^{\prime}}^{\theta k}, 1 \leq \theta \leq m ; i, i^{\prime} \in \Gamma^{O} ; \forall k
\end{aligned}
$$

Where, the value of $\theta$ is determined by the majority rule; if $m$ experts have a common opinion, then the majority rule can adopt the over two-thirds principle or over three-quarters principle. The content of the majority rule can be determined by $m$ experts through joint discussions. After the option according to the majority rule, the common judgment matrix $C_{c o n}^{k}$ of the degree of complementarity and the common judgment matrix $O_{c o n}^{k}$ of the degree of overlap with the common opinion of $m$ experts under the goal $G_{k}$ can be obtained as follows:

$$
\begin{aligned}
& C_{c o n}^{k}=\left\{C C_{i i^{\prime}}^{k} \mid C C_{i i^{\prime}}^{k}=\hat{\alpha}_{i^{\prime}}^{\theta k} ; i, i^{\prime} \in \Gamma^{C} ; i \neq i^{\prime}\right\}, \forall k \\
& O_{c o n}^{k}=\left\{O C_{i i^{\prime}}^{k} \mid O C_{i i^{\prime}}^{k}=\hat{\beta}_{i^{\prime}}^{\theta k} ; i, i^{\prime} \in \Gamma^{O} ; i \neq i^{\prime}\right\}, \forall k
\end{aligned}
$$

Therefore, the closer $C C_{i i^{\prime}}^{k}$ or $O C_{i i^{\prime}}^{k}$ value is to 1 , the greater the degree of complementarity $\left(i, i^{\prime} \in \Gamma^{C}\right)$ or degree of overlap $\left(i, i^{\prime} \in \Gamma^{O}\right)$ of construction projects $t_{i}$ and $t_{i^{\prime}}$ is; on the contrary, the closer it is to 0 , the lower the degree of complementarity or degree of overlap is. If $C_{c o n}^{k}$ matrix and $O_{c o n}^{k}$ matrix are asymmetric matrix, then if $i, i^{\prime} \in \Gamma^{C}$, the values of the degree of complementarity $C C_{i i^{\prime}}^{k}$ and $C C_{i^{\prime} i}^{k}$ of construction projects $t_{i}$ and $t_{i^{\prime}}$ on the performance achievement of goal $G_{k}$ may not be equivalent. If $C C_{i i^{\prime}}^{k}$ is greater than $C C_{i^{\prime} i}^{k}$, then the degree of complementarity of construction project $t_{i}$ to construction project $t_{i^{\prime}}$ is greater than the degree of complementarity of construction project $t_{i^{\prime}}$ to construction project $t_{i}$, and the degree of substitutability of overlapping construction projects has identical properties.

\section{NUMERICAL EXAMPLE}

\section{Problem Background}

Let us assume that local government $X$ plans to carry out a transportation construction to improve the worsening transportation problem and promote local development, and nine feasible transportation construction projects $\left(\Gamma^{T}=\left\{t_{1}, t_{2}, \ldots\right.\right.$, $\left.\left.t_{9}\right\}\right)$ are selected according to detailed planning and evaluation. Local government $X$ plans to achieve goals of economy, environment and life-quality through this large-scale investment. The available resources of local government $X$, such as budget and manpower, cannot meet the requirement of these nine construction projects. Therefore, it is confronted with a decision problem to select a favourable investment project from these nine construction projects.

\section{Decision Limit and Explanation on Handling}

In the nine construction projects, which are complementary projects, and which are overlapping projects? The degree of complementarity of complementary projects and the degree of replaceability of overlapping projects cannot be determined objectively by quantized data. Therefore, local government $X$ plans to let experts from the relevant domains make judgments and evaluations. To keep matters simple, this case assumes that five experts make a group decision to carry out the cooperation-competition analyses and correlativity judgment of the nine construction projects under each goal. 
The relativities of the nine construction projects are different under different goals; in short, we plan to make a description based on a goal $G_{k}$, from among those goals expected to be achieved.

\section{Handling of Decision Problem}

1) Correlativity of Complementary Projects or Overlapping Projects

(1) Determination of Correlativity Among Projects
According to the judgments of five experts, under goal $G_{k}$, nine construction projects are complementary ones and overlapping ones respectively. Five binary complementary judgment matrices $D C^{j k}(j=1, \ldots, 5)$ and five binary overlapping judgment matrices $D O^{j k}(j=1, \ldots, 5)$ can be obtained through (5) and (6). They are shown together for comparison. In elements $a, b, c, d, e$ in the bracket $(a, b, c, d, e), a$ is the judgment value of Expert $1(j=1), d$ is the judgment value of Expert $4(j=4)$, and $e$ is the judgment value of Expert $5(j=5)$.

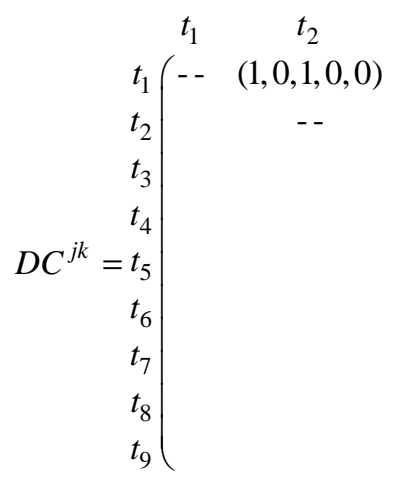

$$
\begin{array}{ccc}
t_{3} & t_{4} & t_{5} \\
(0,0,0,1,0) & (1,1,1,1,1) & (0,1,0,0,1) \\
(0,0,1,0,1) & (1,1,1,1,1) & (0,0,0,0,0) \\
-- & (0,0,0,0,0) & (0,0,0,0,1) \\
& -- & (0,0,1,0,1)
\end{array}
$$

$t_{5}$
$(0,1,0,0,1)$
$(0,0,0,0,0)$
$(0,0,0,0,1)$
$(0,0,1,0,1)$

$t_{6}$

$(1,1,0,0,1)$

$t_{7}$
$(0,1,0,0,1)$

$t_{8}$

$(0,1,1,0,1)$

$t_{9}$

$(0,1,1,0,1)$

$(0,0,1,0,0)$

$(1,0,1,0,0)$

$(0,0,0,0,0)$

$(1,0,0,0,0)$

$(0,0,0,0,0)$

$(0,0,0,0,0)$

$(0,1,0,0,0)$

$(1,1,0,1,1)$

$(0,1,0,1,0)$

$(1,0,1,0,1)$

$(0,1,0,1,0)$

- -

$(0,0,0,0,0)$

$(1,0,0,0,0)$

$(0,0,1,0,0)$

$(0,0,1,0,0)$

- -

$(1,0,1,0,0)$

$(0,0,0,0,0)$

$(0,0,0,0,0)$

Symmetric

--

$(0,0,0,0,0)$

$(0,1,0,1,0)$

$(1,0,0,1,0)$

$\left.\begin{array}{c}--\quad(0,0,0,0,0) \\ --\end{array}\right)$
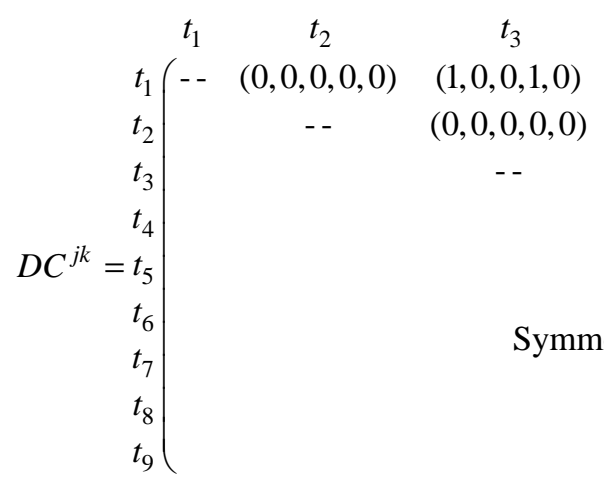

$t_{4}$

$(0,0,0,0,0)$

$(0,0,0,0,0)$

$(0,0,0,0,0)$

- -

Symmetric

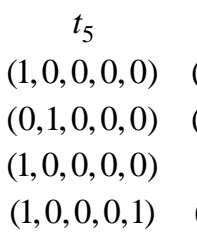

$t_{6}$

$(0,0,0,0,0)$

$(0,0,0,0,0)$

$(0,0,1,0,1)$

$(0,0,1,0,0)$

$(1,1,1,1,1)$

$$
\begin{array}{cc}
t_{7} & t_{8} \\
(0,1,0,0,0) & (0,0,0,0,0) \\
(1,0,1,0,0) & (0,0,0,0,0) \\
(0,0,0,0,0) & (0,1,0,1,0) \\
(1,0,0,0,0) & (0,1,0,0,0) \\
(0,0,1,0,0) & (1,1,1,1,1) \\
(0,0,0,0,0) & (1,1,1,1,1) \\
-- & (0,1,0,0,0)
\end{array}
$$

$\left.\begin{array}{c}t_{9} \\ (0,0,1,0,0) \\ (0,1,0,1,0) \\ (1,0,0,0,0) \\ (0,0,0,0,0) \\ (1,1,1,1,1) \\ (1,1,1,1,1) \\ (0,0,0,0,0) \\ (1,1,0,0,0) \\ --\end{array}\right)$

Combining the judgment results of five experts, synthetic judgment matrices $D C^{T k}$ and $D O^{T k}$ can be obtained to judge whether the nine construction projects are complementary projects and overlapping construction projects according to (7) and (8) as follows:

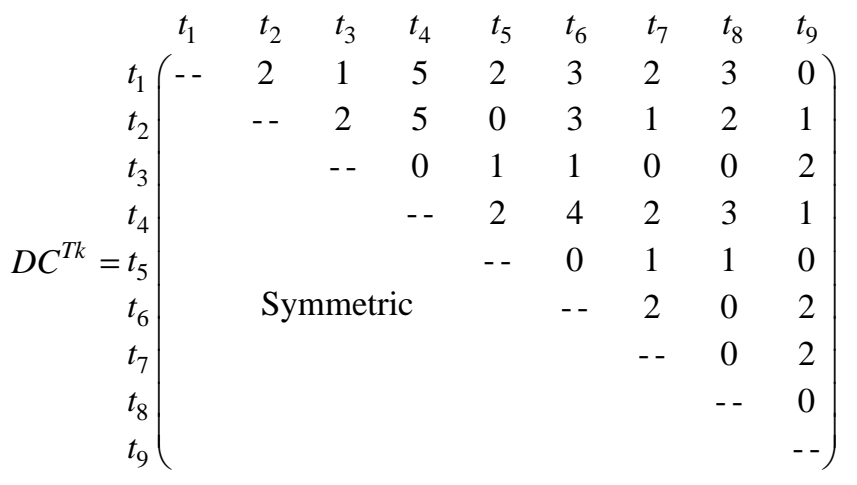

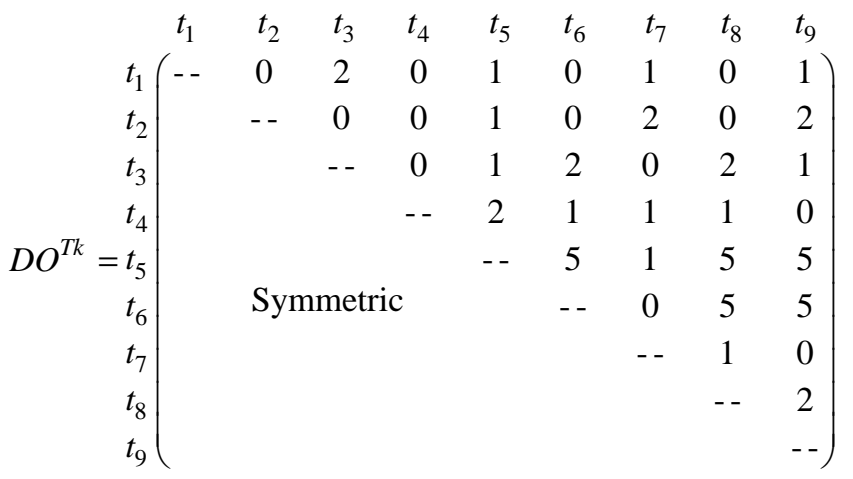

The majority rule determines the adoption of the over threefifths principle after the joint discussions of five experts according to (9) (11), namely, $\theta=3$. As long as three experts have a common opinion, the property of a transportation construction project can be determined. Finally, the com- 
mon judgment matrix $D C_{c o n}^{k}$ of a complementary project and the common judgment matrix $D O_{c o n}^{k}$ of an overlapping project can be determined according to (12) (15) as follows:

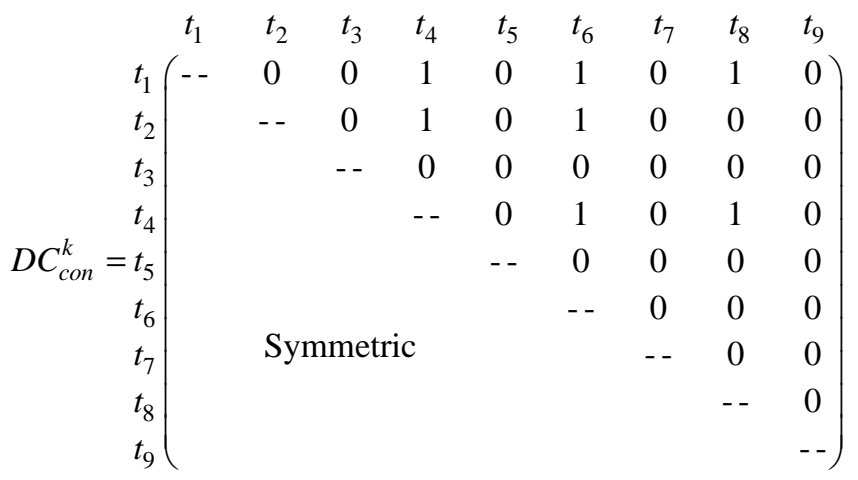

$$
\begin{array}{rlccccccc}
D_{1} & t_{2} & t_{3} & t_{4} & t_{5} & t_{6} & t_{7} & t_{8} & t_{9} \\
& t_{1} \\
t_{2} \\
t_{3} \\
t_{\text {con }}= & 0 & 0 & 0 & 0 & 0 & 0 & 0 & 0 \\
& t_{4} \\
t_{5} \\
t_{6} \\
t_{7} \\
t_{8} \\
t_{9}
\end{array}
$$

(2) Discussion

According to common judgment matrices $D C_{c o n}^{k}$ and $D O_{c o n}^{k}$, the performance achievement of goal $G_{k}$ can be determined to be of a complementary $\Gamma^{C}$ or overlapping $\Gamma^{O}$ construction project:

$$
\begin{aligned}
& \Gamma^{C}=\left\{t_{1}, t_{2}, t_{4}, t_{6}, t_{8}\right\} \\
& t_{1}\left(\begin{array}{l}
t_{1} \\
--
\end{array}\right. \\
& t_{2}(0.2,0.1,0.5,0.3,0.2) \quad(0.1,0.0,0.4,0.2,0.0)
\end{aligned}
$$

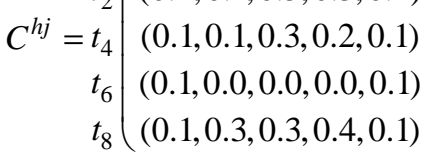

$$
\begin{aligned}
& (0.3,0.0,0.0,0.4,0.2) \\
& (0.0,0.3,0.0,0.2,0.1) \\
& (0.2,0.1,0.0,0.1,0.0)
\end{aligned}
$$

$$
\Gamma^{O}=\left\{t_{5}, t_{6}, t_{8}, t_{9}\right\}
$$

Then, according to the aggregation features of (1) and (2), the complementary and overlapping construction project $\Gamma^{C O}$ and completely independent construction project $\Gamma^{I}$ can be selected:

$$
\begin{gathered}
\Gamma^{I}=\left\{t_{3}, t_{7}\right\} \\
\Gamma^{C O}=\left\{t_{6}, t_{8}\right\}
\end{gathered}
$$

It is shown that two of the nine construction projects are independent projects on the performance achievement of goal $G_{k}$ according to the judgment result of five experts, five are complementary projects, four are overlapping projects and two are common complementary overlapping construction projects. As for the achievement of other goals, the five experts can also use the same method for judgment to obtain the cooperation-competition classification of construction projects under each goal.

\section{Cooperation-Competition Degree of Transportation Construction Projects}

(1) Judgment of the Cooperation-Competition Degree between Projects

According to the cooperation-competition classification result of the nine construction projects, five experts need to judge only the correlativity of five complementary projects and four overlapping projects. After the potential degree of complementarity among five complementary projects is judged by five experts through (16), five judgment matrices of the degree of complementarity $C^{j k}(j=1, \ldots, 5)$ can be obtained. Among them, the $(a, b, c, d, e)$ element represents $a$ as the judgment value of Expert $1(j=1), d$ as the judgment value of Expert $4(j=4)$, and $e$ as the judgment value of Expert $5(j=$ 5).

$(0.2,0.1,0.2,0.1,0.3) \quad(0.4,0.1,0.1,0.3,0.2) \quad(0.0,0.1,0.1,0.0,0.1))$

$(0.7,0.2,0.3,0.6,0.2) \quad(0.2,0.4,0.0,0.3,0.2) \quad(0.0,0.2,0.0,0.0,0.1)$

(0.7.0.2,

$(0.0,0.2,0.0,0.1,0.0)$

$(0.2,0.4,0.1,0.5,0.2)$

$(0.2,0.4,0.0,0.1,0.0)$

$(0.0,0.1,0.0,0.0,0.1) \quad(0.0,0.3,0.0,0.2,0.2)$ through (17), five judgment matrices of degree of substitutability $O^{j k}(j=1, \ldots, 5)$ can be obtained as follows:

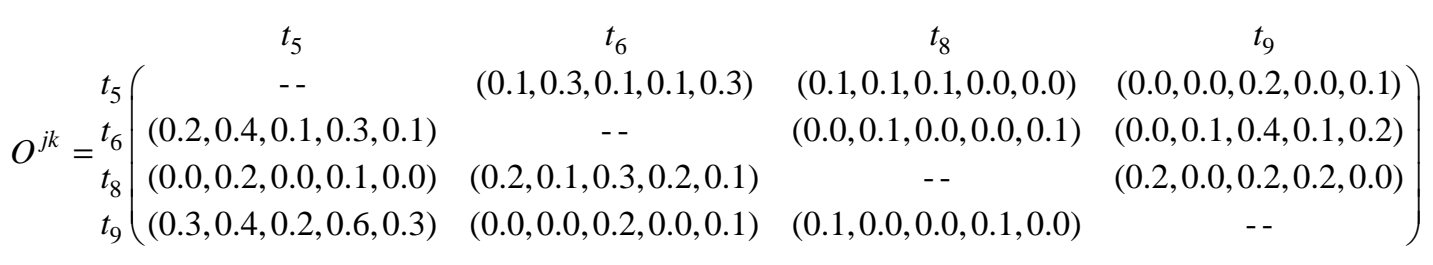


Then, arranging five experts' judgment values on the potential degree of complementarity of five complementary construction projects and the judgment values on the potential degree of substitutability of four overlapping construction projects from the maximum to the minimum, the synthetic judgment matrix of degree of complementarity $C^{T k}$ and the synthetic judgment matrix of degree of substitutability $O^{T k}$ can be obtained as follows:

$$
\begin{aligned}
& t_{1} t_{2} \\
& t_{1}\left(\begin{array}{cc}
t_{1} & t_{2} \\
t_{2} & (0.4,0.2,0.1,0.0,0.0)
\end{array}\right. \\
& (0.3,0.2,0.2,0.1,0.1) \\
& (0.7,0.6,0.3,0.2,0.2) \\
& (0.4,0.3,0.2,0.0,0.0) \\
& (0.3,0.2,0.1,0.0,0.0) \\
& \text { - - } \\
& (0.4,0.2,0.1,0.0,0.0) \\
& t_{6}(0.1,0.1,0.0,0.0,0.0) \\
& (0.2,0.1,0.1,0.0,0.0) \\
& (0.1,0.1,0.0,0.0,0.0) \\
& \begin{array}{c}
(0.4,0.3,0.2,0.1,0.1) \\
(0.4,0.3,0.2,0.2,0.0) \\
(0.2,0.1,0.0,0.0,0.0) \\
-- \\
(0.3,0.2,0.2,0.0,0.0)
\end{array}
\end{aligned}
$$

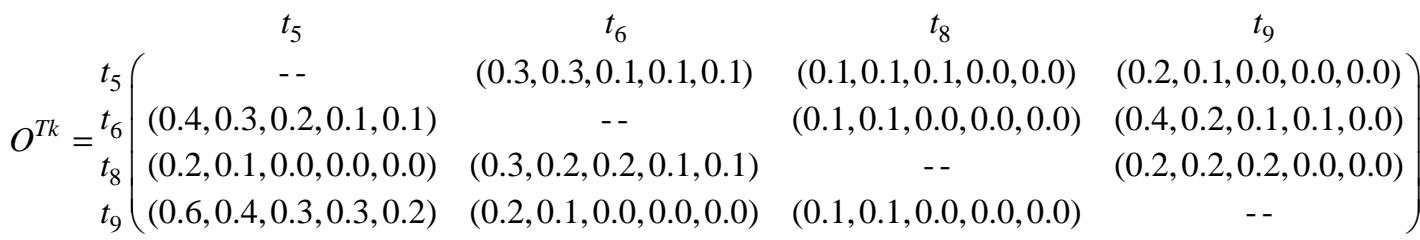
$(0.1,0.1,0.0,0.0,0.0)$

It is decide to adopt the over three-fifths majority rule as the principle after the joint discussion of three experts through (20) and (21), so that at least three of the five experts have a common opinion, and then the degrees of complementarity $C C_{i i^{\prime}}^{k}$ and $C C_{i^{\prime} i}^{k}\left(i, i^{\prime} \in \Gamma^{C}\right)$ of complementary construction projects and the degrees of substitutability $O C_{i i^{\prime}}^{k}$ and $O C_{i^{\prime} i}^{k}\left(i, i^{\prime} \in \Gamma^{O}\right)$ of overlapping construction projects can be determined. According to (22) and (23), $\theta=3$ is taken to determine the complementary common judgment matrix $C_{c o n}^{k}$ and the overlapping common judgment matrix $O_{c o n}^{k}$. Finally, the two matrices are obtained as follows:

$$
\begin{aligned}
& \begin{array}{lllll}
t_{1} & t_{2} & t_{4} & t_{6} & t_{8}
\end{array} \\
& t_{1}\left(\begin{array}{lllll}
-- & 0.1 & 0.2 & 0.2 & 0.1
\end{array}\right) \\
& \begin{array}{l|lllll}
t_{2} & 0.2 & -- & 0.3 & 0.2 & 0.0
\end{array} \\
& C_{\text {con }}^{k}=\left\{C C_{i i}^{k}\right\}=t_{4} \mid \begin{array}{llllll}
0.1 & 0.2 & -- & 0.0 & 0.2
\end{array} \\
& \left.\begin{array}{c|ccccc}
t_{6} & 0.0 & 0.1 & 0.1 & -- & 0.0 \\
t_{8} & 0.3 & 0.1 & 0.0 & 0.2 & --
\end{array}\right) \\
& O_{c o n}^{k}=\left\{O C_{i i^{\prime}}^{k}\right\}={ }_{t_{6}}\left(\begin{array}{ccccc}
t_{5} & t_{6} & t_{8} & t_{9} \\
t_{8} & - & 0.1 & 0.1 & 0.0 \\
t_{9} & 0.2 & -- & 0.0 & 0.1 \\
0.0 & 0.2 & -- & 0.2 \\
0.3 & 0.0 & 0.0 & --
\end{array}\right)
\end{aligned}
$$

\section{(2) Discussion}

According to the common judgment result of five experts on the achievement of goal $G_{k}$, the degrees of complementarity $C C_{i i i^{\prime}}^{k}$ and $C C_{i^{\prime} i}^{k}$ between pairwise construction projects of complementary construction projects are not equivalent. For example, $C C_{12}^{k}=0.1$ and $C C_{21}^{k}=0.2$ mean that if construction project $t_{1}$ and construction project $t_{2}$ are selected at the same time, on the performance achievement of goal $G_{k}$, construction project $t_{1}$ can increase the goal achievement value of construction project $t_{2}$ by $10 \%$, and construction project $t_{2}$ can increase the goal performance achievement value of construction project $t_{1}$ by $20 \%$.

Similarly, on the overlapping construction project, $O C_{i i}^{k}$ and $O C_{i^{\prime} i}^{k}$ are not equivalent; for example, $O C_{56}^{k}=0.1$ whereas $O C_{65}^{k}=0.2$. Therefore, if construction project $t_{5}$ and construction project $t_{6}$ are selected at the same time, on the performance achievement of goal $G_{k}$, construction project $t_{5}$ can replace $10 \%$ of the achievable goal performance of construction project $t_{6}$, and construction project $t_{6}$ can replace $20 \%$ of the achievable goal performance of construction project $t_{5}$.

The degree of complementarity and degree of overlap of other goals can also be determined through the same method according to the cooperation-competition classification result under each goal. Furthermore, according to the relativity of each goal achievement, the increased or decreased goal achievement performance can be calculated and then used as the basis of construction project selection.

\section{CONCLUSION}

Transportation construction projects have a certain degree of relativity under a goal to be achieved; therefore, when choosing projects, a division of levels should be made according to the priority of project desirability. This research identified the relativity of potential cooperation-competition between projects to avoid any waste of limited investment resources. The results showed that the cooperation-competition relation of construction projects could be classified as an independent project, a complementary project, an overlapping project, and a common complementary overlapping project. Future studies based on the results of this research will carry out the con- 
struction of a multi-annual budget allocation model under the government's multi-objective and limited resources.

\section{ACKNOWLEDGMENTS}

The authors are grateful for the helpful comments made by the editor of this journal and the anonymous reviewers. We also like to thank colleagues in the department for their valuable feedback.

\section{REFERENCES}

1. Arrow, K. J., "Criteria for social investment," Water Resources Research, Vol. 1, pp. 1-8 (1965).

2. Baker, N. R. and Freeland, J. R., "Recent advances in R\&D benefit measurement and project selection method," Management Science, Vol. 12, No. 10, pp. 1164-1175 (1975).

3. Carlsson, C., "Tackling an MCDM-problem with the help of some results from fuzzy set theory," European Journal of Operational Research, Vol. 10, No. 3, pp. 270-281 (1982).

4. Chankong, V. and Haimes, Y. Y., Multiobjective Decision Making: Theory and Methodology, Elsevier, Amsterdam, Netherlands (1983).

5. Fayette, J. R., "Appraisal of non-independence projects," in: Nijkamp, P. and Spronk, J. (Eds.), Multiple Criteria Analysis: Operational Methods, Gower, England, pp. 137-152 (1981).

6. Feldstein, M. S., "The social time preference discount rate in cost-benefit analysis," Economic Journal, Vol. 74, pp. 360-379 (1964).

7. Gear, T. E., "A note on modeling project interdependence in research and development," Decision Sciences, Vol. 11, pp. 738-748 (1980).

8. Hwang, C. L. and Masud, A. S. M., Multiple Objective Decision Making-Methods and Applications: A State of the Art Survey, Springer-Verlag, New York (1979).

9. Kay, J. A., "Social discount rate," Journal of Public Economics, Vol. 1, pp. 359-378 (1972).

10. Keeney, R. L. and Raiffa, H., Decisions with Multiple Objectives: Pref- erences and Value Tradeoffs, John Wiley and Sons, New York (1976).

11. Khorramshahgol, R. and Steiner, H. M., "Resource analysis in project evaluation: A multicriteria approach," Journal of the Operational Research Society, Vol. 39, No. 9, pp. 795-803 (1988).

12. Kula, E., "Future generations and discounting rules in public sector investment appraisal," Environment and Planning A, Vol. 13, pp. 899-910 (1981).

13. Leinbach, T. R. and Cromley, R. G., "Modeling integrated development investments in rural area: An Indonesian illustration," International Regional Science Review, Vol. 12, No. 2, pp. 229-243 (1989).

14. Morisugi, H., "Measurement of road user benefits by means of a multiattribute utility function," Papers of the Regional Sciences Association, Vol. 46, pp. 31-43 (1981).

15. O'Leary, T. J., "The cost/ benefit analysis: It can be a misleading tool for transportation planners," Transportation Planning and Technology, Vol. 5, pp. 189-193 (1979).

16. Pearman, A. D., Mackie, P. J., May, A. D., and Simon, D., "The use of multicriteria techniques to rank highway investment proposals," in: Lockett, A. G. and Islei, G. (Eds.), Improving Decision Making in Organizations, Springer-Berlag, London, pp. 157-165 (1989).

17. Saaty, T. L., The Analytic Hierarchy Process, McGraw-Hill, New York (1980).

18. Teng, J. Y. and Tzeng, G. H., "A multiobjective programming approach for selecting non-independent transportation investment alternatives," Transportation Research B, Vol. 30, No. 4, pp. 291-307 (1996).

19. Teng, J. Y., Yeh, R. C., Lin, M. C., and Huang, W. C., "The budget allocation of transportation construction projects by fuzzy multicriteria grade classification model," Journal of the Eastern Asia Society for Transportation Studies, Vol. 7, pp. 415-426 (2007).

20. Tzeng, G. H. and Teng, J. Y., "Transportation investment project selection with fuzzy multiobjective," Transportation Planning and Technology, Vol. 17, pp. 91-112 (1993).

21. Voogd, H., "Multicriteria evaluation: Measures, manipulation, and meaning- a reply," Environment and Planning B, Vol. 15, pp. 65-72 (1988).

22. Zeleny, M., Multiple Criteria Decision Making, McGraw-Hill, New York (1982). 